\title{
Agendas for the Historical Study of Loneliness and Lone Living
}

\author{
K. D. M. Snell* \\ Centre for English Local History, University of Leicester, UK
}

\begin{abstract}
This article opens up approaches and themes for a history of loneliness. It advocates handling of the subject by historians, and invites historical analysis of concepts, health issues, strategies from the past, theories of long-term loneliness change, 'nuclear family hardship' and related demography. Topographies of isolation are raised. It then discusses one aspect of this: considering how living alone often seems to shape modern discussion of loneliness, and analysing the steep rise of sole living in Western societies over the past century.
\end{abstract}

Keywords: Ageing, aloneness, individualism, isolation, loneliness, nuclear family, solitaries, singletons, the elderly, welfare.

\section{INTRODUCTION AND HISTORICAL QUESTIONS}

Does loneliness have a history? The historical study of this emotion has only just begun, and we are currently at the stage of raising questions and establishing an agenda, sociology, and across modern welfare disciplines, and despite the modern public, political and media concern about an 'epidemic' or 'time bomb' of loneliness, historians have been slow to explore historical aspects of the problem. The history of emotions is a relatively new area of research, and loneliness is an emotion not yet included among those for which historical studies exist, despite appreciation of the value of studying historical narratives and shifting meanings of loneliness [1]. Indeed, in general surveys of the history of emotions there is usually no entry of any sort for loneliness or its allied concepts, just as there are often no entries for loneliness in psychiatric or psychological textbooks. It seems slower to catch the historical imagination than fear, love, anger, jealousy, aggression, tears, the smile (all of which have their historians), or the meanings of envy as studied by anthropologists. Indeed some historians have shied away from loneliness, almost as if its study would aggravate the research isolation that many of them feel in a relatively individualistic academic discipline. There is little doubt that fear of loneliness in the past has been a major factor in decision making of many kinds, affecting for example leaving home, marriage, migration and emigration, old age planning, systems of insurance and formal welfare, kinship connectivity and much more. It is therefore crucial for historians to study the history of loneliness, both to augment historical understanding, and to help set urgent modern issues into a long-term framework or theory of historical change.

This sets a huge agenda, with a plethora of questions which cannot as yet be answered. How far is loneliness a Despite salient research on loneliness in psychology modern

*Address correspondence to this author at the Centre for English Local History, University of Leicester, UK; E-mail: kdm@le.ac.uk problem? Why has it become salient now? Was it a problem in the past? What were the historical experiences and causations of loneliness? What are its demographic links, and why has it often now become focused upon 'solitaries', for (rightly or wrongly) they seem to shape many issues of modern loneliness? What cultural and international forms has it taken? How have its feelings, constructions and expressions changed? How in history and across cultures does it relate to solitude, aloneness, homesickness, anomie, alienation, privacy, and related concepts, and how in past personal experiences did these elide into each other? What remedies, therapies or health precautions does the past show for loneliness? After outlining some of the main justifications, issues and concepts, this article will focus upon the historic rise of solitaries or singletons. It does so without wishing to prioritise these in loneliness research, though they are to the fore in much loneliness discussion.

The coverage here will mainly be for the period 17002015. Yet clearly there is a longer term vista of potential research, when one thinks back for example to such earlier topics as the Icelandic sagas and their accounts of banishment and judicial outlawry, to medieval traditions of hermitage and isolated monasticism (e.g. Ynys Enlli, Skellig Michael, etc), to the ideal of peregrinatio and its selfimposed exile, to many of the medieval strands of contemplative scholasticism, to the possible roles of religion as threat averting or coping vis-à-vis loneliness, to earlier diasporas and fragmentary settlements, or to early modern or medieval fears of isolated people, such as 'witches', and their resulting persecutions.

The historical questions are important because loneliness is such a fundamental social and political issue today. It is crucial in sociology, psychology and social work. It raises major issues of different regional and global experiences, for it is apparent that loneliness and allied concepts are differently constructed and experienced across cultures [2]. It is also relevant to 'the challenge of affluence' [3], for loneliness not only affects the dispossessed, the elderly or educationally disadvantaged but in modern forms can 
sometimes be a by-product of purchased privacy. It invites many historical answers to questions about strategies, remedies and health effects; and it has huge demographic import. Population change and the processes of the second demographic transition, with its social changes implicated in a rapid rise in numbers of smaller households, implies trajectory towards ever greater isolation. Yet loneliness has no written or comparative history.

\section{HEALTH ISSUES}

Loneliness is now diagnosed as an 'epidemic', or according to the British Office for National Statistics a 'loneliness time bomb' [4-6]. Doctors report patients asking: "Can you give me a cure for loneliness?" They humanely discuss in the British journal The Lancet the role of antidepressants, and patients "for whom time now stands empty as they wait in homes full of silence...It brings home to me the truth of this epidemic - an epidemic of loneliness...I don't know how to solve this, although I wish I could" [4, p. 2114-5]. Its extent is widely appreciated. North American and British studies show that 30-50 per cent of those surveyed feel lonely. Around 10-25 per cent report severe loneliness [7-9]. The statistics may be worsening. The UK Mental Health Foundation (2010) found that only 22 per cent of people surveyed never felt lonely, and 42 per cent have felt depressed through loneliness. Loneliness especially afflicts very young adults and the elderly $[10,11]$, much like suicide. It is evident or even growing among children [10, 12,13 ]. A long line of studies has shown that loneliness is "a well-known calamity of old age" [14-17]. Rising life expectancy in a frequent context of divorce, separation, or mortality-broken marriages exacerbates this.

The medical literature on loneliness is growing rapidly, and showing great concern $[10,18]$. "Despite its pervasiveness...loneliness has only recently been described and treated as a unique clinical problem" [19]. Yet it is now quite frequently argued that loneliness has health effects akin to smoking $[10,11,20,21]$. Self-rating assessments of loneliness, notably the widely used and credited UCLA Loneliness Scale [22], and the equivalent European scales, correlate strongly with living alone, and with increased incidence of heart attacks, strokes, cancers, bulimia nervosa, drug abuse, unhealthy diets/over-eating, less exercise, sleep deprivation, depression, alcoholism, anxiety, and premature death [7, 9, 11, 23-33]. In many countries, such as North America and Japan, and across age groups, loneliness is a foremost cause of suicide, also sharing its contexts and seasonality [7, 19]. Loneliness has biochemical effects, decreasing immune response, increasing blood pressure, conducing to atherosclerosis, accelerating ageing processes. American loneliness has been said to be "one of the nation's most serious public health challenges" [34, p. 327]. While it is often hard to analyse cause and effect, loneliness precedes and results from illness. It links to widowhood, divorce, low education and pay, unhappiness and limited resources [9, 35]. It even connects to domestic violence. There appears to be clustering and familial transmission, inviting input from attachment and other psychological theory [3]. In a downward spiral, loneliness often induces diminishing ability to create relationships [10]. These issues have received extensive international, media and political attention.

\section{DEFINITIONS, CONSTRUCTIONS AND THEMES FOR STUDY}

One author has written of "the searing pain of loneliness" [7, p. 335], and another of "a quality of living death" connected to it [36, p. 48]. There is no doubt about its severe effects. Yet what is meant by the term, and are modern meanings applicable historically? There has been much discussion of forms of loneliness, ways of defining these, and their contexts and correlates. Some of the sociological and psychological literature distinguishes many 'types' of modern loneliness, even subjecting them to detailed quantitative analysis. These include concepts of loneliness variously described by authors as chronic, situational, transient, cultural, cosmic, social, interpersonal, emotional, existential, desolating, reactive, pathological, and psychological [10, 19, 37-39]. These have complex potential interactions, and a research and source-specific question for historians is the changing relationships between them, and between loneliness, aloneness and living alone. Historians also have to handle terms such as melancholia, which in some clinical or welfare settings are described as overlapping with or embodying loneliness. In addition, some concepts of loneliness are 'objective', for example another person's judgement about lack of social support for someone; while others are subjective, as perceived by the subject. This can also depend on the context of discussion, the question of need, or the form of expression. For example, an official letter admitting a patient to a nineteenth-century asylum may 'objectively' comment upon the loneliness and isolation apparently suffered by the patient with 'melancholia'; or, more subjectively, an eighteenth-century diarist such as Thomas Turner may write of his intense loneliness upon bereavement and his wife's death [40]. It would appear that for all periods the lonely perceive themselves, or are perceived, as lacking social support and confiding relationships, and in some literary descriptions they also seem to lack informational links to their wider environment or communities.

A working definition of loneliness which can be agreed by historians is that supplied by Andersson: "the generalised lack of satisfying personal, social, or community relationships". Loneliness comprises "an enduring condition of emotional distress that arises when a person feels estranged from, misunderstood, or rejected by others and/or lacks appropriate social partners for desired activities, particularly activities that provide a sense of social integration and opportunities for emotional intimacy" [18, p. 265]. Loneliness arises "when there is a perceived deficit or dissatisfaction of the quality or the quantity of social interactions... it is the perceived gap between the expected and the actual social relations that account for loneliness" [11, p. 1382]. The degree of voluntary control a person has over the situation helps to distinguish between loneliness and solitude, between negative or positive feelings about such a condition.

It is essential to distinguish the apparently 'objective' aspect of aloneness, and loneliness, which can occur among 
others. One is the objective state of being alone or in solitude, which may well be a desired and non-lonely situation, akin to an outcome of satisfied privacy. The other is the subjective state of feeling lonely, which may occur in personal isolation, or may be felt among others, even among countless others, as perhaps in a modern city. Aloneness, solitude and loneliness are clearly not the same. There are, however, two main points to make in this connection. First, research indicates situational aloneness and subjective selfrated loneliness frequently (though not necessarily) occurring together, suggesting a need for linked analysis, which will be advanced below in discussion of solitaries. In most regression-type studies of loneliness, the most significant explanatory variable is living alone, with attendant variables such as widowhood and bereavement. The fact that living alone has undergone such extraordinary growth over the past half century in advanced economies therefore raises ancillary questions about loneliness, notably in Western cultures. (This of course is not to prioritise loneliness of solitaries, nor to suggest that they are necessarily lonely. Acute loneliness is suffered by many who do not live alone). Second, the modern 'problem' of loneliness is one that has, whether correctly or otherwise, often come to be associated with or even shaped by the growing incidence of living alone. In other words, to understand why that connection has established itself, and to judge its analytical utility or partiality of perspective, we initially need to uncover trends in the prevalence of living alone: of what in North America are termed 'singletons', and in Britain 'solitaries', sharing the similar French word. These terms mean the same: a household comprising one person. For discussion here, 'household' is defined as a set of people who live and eat together or a person living alone, which combines housing and housekeeping definitions of household, and follows official common usage [41].

It is frequent for historians to query the historical applicability of sociological and psychological theory, and in connection with human isolation the theoretical sociological/philosophical literature is very rich indeed. Sociology in effect is the study of the individual in society. And there is no doubt that loneliness is much affected by cultural heritage [2]. Relevant discussion and theory includes the French writer de Tocqueville's remarkable study of human isolation, 'egoism' or individualism, Democracy in America [42], or the early sociologists Engels, Tönnies, Durkheim, or Simmel. For example, Durkheim explored the cult of the individual, while Simmel developed theory on individuation, and the subjective effects of metropolitan life. The genre includes many existential authors, such as the French writers Sartre, Camus or Genet, through to a wide array of modern authors such as Colin Wilson, Beck, Bauman, Pahl or Connerton. Any such list would include many classics of American sociology, by authors such as Robert Bellah, Christopher Lasch, Robert Putnam, David Riesman, Philip Slater or Maurice Stein. North Americans for over fifty years have been assailed with academic information about how lonely they are, or about how free they are, to be alone. The historiography of this academic story has become a perceptual part of the modern history of loneliness. Such diagnosis takes one back a long way. In an early account of the modern city, Friedrich Engels, paradoxically one of the most important precursors of such analyses, wrote about how:

The brutal indifference, the unfeeling isolation of each in his private interest becomes the more repellent and offensive, the more these individuals are crowded together, within a limited space...this isolation of the individual, this narrow self-seeking is the fundamental principle of our society everywhere.

Engels, in anticipation of countless modern urban theorists (and ignoring evidence of rural isolation), saw this "dissolution of mankind into monads" as an attribute especially of great towns: "Everywhere barbarous indifference, hard egotism on one hand, and nameless misery on the other... [One] can only wonder that the whole crazy fabric hangs together" [43, p. 58].

Ferdinand Tönnies, who had read Engels, thought that "living together is a primal fact of nature, it is isolation, not co-operation, that needs to be explained". He described a shift to an "absolutely detached cosmopolitan and universalist individualism" [44, p. 38]. These views echo those of de Tocqueville, in his assessment of the newness of American individualism and its forms of capitalist human interaction. In such theorising, isolation and loneliness become intrinsic to modern society - the historical presumption is suggestively clear, that modernity often brings chronic loneliness. Many have subsequently argued that North American, British and north European cultures have intensified loneliness, given individual competitiveness and impersonal metropolitan living [45, 46]. Ulrich Beck wrote:

The designs of independence become the prison bars of loneliness... The form of existence of the single person is not a deviant case along the path of modernity. It is the archetype of the fully developed labor market society. The negation of social ties that takes effect in the logic of the market begins in its most advanced stage to dissolve the prerequisites for lasting companionship... [This] certainly fits an increasing segment of reality...the end of this road is...isolation in courses and situations that run counter and apart from each other [45, p. 123].

Beck argued that community beyond the family is in decline; that growing individualisation is precarious, notably with economic uncertainty. Social ties become reflexive, needing to be maintained by individuals. There are rarely longer networks or communities into which people are born and take for granted as framing them and giving them firm communal identities. Thus isolation and loneliness become major social features, especially among groups like young adults or the elderly. This theme of the logic of capitalism vis-à-vis personal isolation and loneliness is frequent, albeit varying in academic and cultural exposition. Substitutive investment in commodities, rather than in personal relationships and social obligations, is often held to be a concomitant feature of capitalism; and if the psychology of such substitution is well founded, then capitalism warrants historical analysis as having a stake in the intensification of loneliness.

Such judgements have sometimes been assuaged by an acknowledgement that isolation also brings benefits, such as 
creativity in solitude. This is after all a field abounding in conflicting value assessments, in 'pessimistic' [45, 47], or more 'optimistic' accounts [21]. Even so, these modern concerns require a non-judgemental chronological framework. Despite the implications for loneliness studies of individualised Romanticism, or of literary and cultural modernism, we have little idea yet what that historical framework might look like. The presumptions in much theoretical and descriptive literature should open an agenda for cross-cultural historians. Can one construct a chronological schema or historical framework for subjective loneliness change: such as a process of transitions from, firstly, what we might call archaic loneliness (which would be largely rural, and may at the extreme be linked to varying religious traditions of hermeticism, monasticism, or contemplation); through secondly, to proto-modern conceptions of loneliness associated with rural depopulations, increasing secularisation and the rise of big cities; through thirdly to 'modern' types of loneliness, which one would see as underpinning many forms of artistic modernism, most notably in the period c. 1870-1930; and now, fourthly, to types of loneliness allied to the striking rise of singletons or solitaries, by which is partly defined the 'second demographic transition' [48, 49]. Some classics of loneliness and related topics, notably Daniel Defoe's Robinson Crusoe [50], or Robert Burton's The Anatomy of Melancholy [51], of course predate modernism. But it is perhaps with modernism and secularisation that loneliness most features in art, literature and science. This literary and historical view is quite widely found, including the very defining of 'modernism' as the experience of loneliness. Yet these are huge historical questions, focused upon the possibly shifting theme and conception of loneliness, and they imply major and eclectic historical research agendas. As yet we know almost nothing about the implications for loneliness of key historical markers, such as the Black Death, or the Reformation, or the rise of Puritanism, or the slave trade, or industrialisation, or rural out-migration, urbanisation, or mass emigrations, or the social changes after the Second World War, or the women's movements, or the first or second demographic transitions. To what extent were these significant as historical watersheds against which to interpret shifts in the meanings and incidence of loneliness?

Nor is there much explicit anthropology, archaeology or economics of loneliness, just as it has no written history. Anthropology, however, might be thought of as an academic compendium of lonely travellers' stories. Leaving aside the predicaments of Malinowski and his followers, it opens countless questions. For example, is the severity of loneliness a proxy for the extent to which a society values close emotional relationships? How have ancestors been seen as aids to the loneliness of the living, a question that extends to modern family history? Or in economics, consider market responses to loneliness; or its relevance to models of choicemaking, or of risk aversion; or the potential economics of isolation; or the health-care economic ramifications of loneliness; or the psychological needs of consumption. Loneliness in such connections raises many historical and developmental issues. The implications of forms of international capitalism and growing affluence remain unclear: 'atomistic' migrant, wage-dependent individuals, and 'self-resilient' ideologies, may render people especially prone to loneliness, as many eminent American sociologists have expounded. However, trade and markets promote communication, interactions and technologies which probably reduce loneliness. These issues about loneliness are fundamental to the human sustainability of capitalistic or comparative economic systems, as for example in historical comparisons between the USA and China, though the loneliness and ostracism of migrants to Chinese cities is a major problem, alongside the ageing population against a backdrop of severe fertility reduction. Many of these historical questions and judgements are influenced by social science discussions about whether the causes of loneliness are person-centred, situational/cultural, or social-system derived. These are complex debates which clearly have implications for the scope of historical enquiry - just as historical answers have implications for the social science debates.

Meanings of loneliness are assuredly influenced by age, gender, culture - it has been differently experienced, socially constructed and seen $[1,2,52]$. Most historians, through their experiences of historical variability, would probably openly or implicitly ally themselves in varying degrees to social constructionist positions with regard to emotions. Where has loneliness occurred, or been variously constructed? In recent years, north-west European societies report somewhat lower loneliness than southern Europe. ExUSSR countries indicate high rates of loneliness [11, 53]. Severe political and economic changes, and resulting migrations, have caused considerable dislocation, conducing to high loneliness in the 2006-7 European Social Survey. What comparable effects did industrialisation hitherto produce? Little is known about contrasting regional historical/cultural experiences, perceptions, constructions, social functions, gendering, possible ostracism of loneliness, its relation to social and power structures, or to affluence. Different languages have culture-specific terms, or in some cultures elide loneliness and solitude together, in ways that many individualistic academics in the west significantly prefer to keep apart.

Analysis is thus needed of cultural meanings and historic constructions of loneliness, and the relation between similar concepts. This extends to the terminology of allied words to loneliness (solitude, desolation, melancholy, isolation, privacy, etc), which partially overlap the concept of loneliness, as do many historical and current psychological terms. So would concepts such as Durkheim's anomie or Marx's alienation with its later meanings. Or there are expressions of existential anxiety or disenchantment, from the atmosphere of lonely strangeness or powerlessness in Kafka's The Castle or Metamorphosis, to the unreality and indifference of Meursault in Camus' L'Etranger, to the sceptical disconnection of Roquentin in Sartre's La Nausée. Other issues are raised here of 'freedom' as a relief from isolated unreality. One thinks of striking and culturally nuanced expressions of loneliness in well-known and often prolific American writers such as Walt Whitman, Herman Melville, William Faulkner, J. D. Salinger, or Charles Frazier. The expressions of loneliness in American song and ballad would require a book to analyse, written by only the lonely in some blue bayou or heartbreak hotel covering the 
waterfront, awaiting their portrait by Edward Hopper. Then again, one notes the modern sociological language of 'atomisation', and its expression in recent existential novels such as Atomised by Michel Houellebecq [54]. Such concepts have been subject to varying psychological, public, artistic and critical usage. They are forms of loneliness, and have wider applied, theoretical or phenomenological meanings.

The past is an extensive array of options as well as an explanatory transmission to the present. Much psychological and medical literature concerns strategies for loneliness, which could benefit from historical perspectives, for example from periods in which ideas of 'community' were administratively more structured than is now usually the case. What forms have these strategies hitherto taken? How were social and emotional needs assessed, and by whom? What were support networks for the lonely? How have they changed? Related issues concern fear of loneliness [55]. This extends to fear or marginalisation directed at those who are lonely, of which there were many historical and stigmatising forms - for lonely people induce guilt, shame, anxiety or self-doubt in others, impacting in psychological or practical ways upon them. How historically has loneliness-related fear affected risk-aversion behaviour: marriage (or marriage avoidance) decisions, kin-connectivity, migration, savings, technologies, formal and informal welfare provision, or preparation for old age? After all, marriage is (or has been) often sustained by what is feared beyond or without it.

Have communication technologies been responses to loneliness? They helped to assuage it. Most technologies arise from a felt need for them, as with mobile phones and internet social media. Yet some technologies have reduced face-to-face human contact, providing senses of distanced social action. Such technologies may instil loneliness, undermining potential for shared experience. Cinema for example induced silent togetherness, often watching films about lonely people: as outlined in A Cinema of Loneliness. Its author comments on how "passivity and aloneness... have become their central image. When they do depict action, it is invariably performed by lone heroes in an enormously destructive and antisocial manner" [56, p. 10]. Leaving aside the genre of high plains drifters or late night taxi-drivers, there was also the wireless, which brought canned laughter and thus make-believe 'community' to isolated people. Further, implications for loneliness of changing technologies and methods of travel remain unclear, for these have been very mixed in their effects: on personal senses of place, belonging or displacement, on street social interactions, isolation of passengers, or propensities to bring people together $[46,57]$.

Issues of secularisation are also important, given ideas of a divine personal 'friend' with whom one is never alone, and religious senses of belonging and community [58, 59]. Senses of personal isolation and loneliness permeate religious sensibilities and texts. There is no loneliness in anybody's Heaven. Prayer and spiritualised diaries are otherdirected conversation, to a personalised God, but these are increasingly abandoned in the west, along with the community structures of prayer. Modern studies suggest that religion is threat-averting vis-à-vis loneliness [60], and
Rokach [7] has written of how religion may offer a way of coping with loneliness. This poses historical questions about religion as protection against loneliness, to overcome solitude and achieve intimacy [61], notably in contexts of urbanisation, dislocation, emigration or frontiers. Further, as in forms of evangelical Protestantism, stressing liberty of the isolated self, it raises issues about the psychological despair of those who have felt themselves forsaken by God.

\section{TOPOGRAPHIES OF LONELINESS}

Isolation in the form of singletons has been regionally varied, and has changed through time. In the UK for example, modern living alone (in the 2001 and 2011 censuses) is high in outlying largely rural regions, in retirement areas, in zones of scattered settlement, and especially in cities. Such a demographic geography is shared by many other countries, such as Scandinavia, Canada, or Japan. There were historical topographies of loneliness, linked to landscape, social networks and occupations - the modern city has now been added to these, as in many modern novels, though eighteenth-century cities were not seen as lonely places. To judge from historical and literary documentation, and the regionality of some occupations, certain environments have been ecological niches or domains of loneliness. To take one striking example, the huge Yukon region of Canada has been described, in autobiographical account from the 1930s, as extreme in its isolating and loneliness-inculcating nature, with settlers, prospectors or trappers often not seeing anybody for months on end. One of the important functions of the Royal Canadian Mounted Police was to keep an eye on such people, even at the risk of hazardous personal journeying in periodical visits to check on such singletons' mental health [62]. Many other occupations have been documented for their isolating and lonely nature, such as farmers, shepherds, gamekeepers [63], or lighthouse men [64]. Loneliness historically was often reported as affecting minority groups, who felt themselves isolated in an overriding culture, such as North American Indians, Turkish workers in Germany, Australian Aborigines (whose own loneliness had been a 'walkabout' rite of passage), or many European ethnic minorities such as gypsytravellers. Disability and sometimes related ostracism (which could be extreme in the past), certain forms of ill-health, lodging in 'less eligible' institutions like workhouses, and orphanage have also often been disposing conditions for loneliness. Equivalent predicaments today are widely discussed, but alertness to these and to their associated problems or strategies lacks historically studied counterparts.

\section{LIVING ALONE NOW AND IN THE PAST}

Such issues and evidence bearing upon loneliness need to be refigured as an historical genre on loneliness, that might extend the impressive scope of medical and social science studies. In particular, demographic and household analyses help resolve some of the historical questions, and, in study of the subjective and contextual phenomenon of loneliness, may begin to insert a suggestive historical narrative. I take loneliness to be a universal or ubiquitous aspect of consciousness (as an internal condition existentially understood, tied to psychological understanding of the 
separation of self from others), one that is however shaped and often much magnified by external sociological, cultural and historical conditions or causes, such as living alone, individual mobility, modes of production and so on. Attention to the effects of historical family structure is, in this context, expected and highly relevant.

There has been remarkable growth in single-person households, and living alone is persistently shown in American, British and European post-1950s analyses to be significantly correlated with loneliness [23, 28, 33, 37]. An association between lone-person residency and loneliness is certainly not a necessary one, for otherwise rates of modern loneliness would be enormous, yet it is frequently evident in historical and literary sources. This clearly invites historical questions about long-term trends in living alone and who was thus affected.

Historical demographers are familiar with many periods of extreme sex ratios and inevitable singleness: inter-war Europe following high male mortality; regions such as west Wales or west Ireland experiencing high gender-specific outmigration [65, 66]; many areas of heavy industry attracting male workers; the nineteenth-century American frontier; or other emigrant-receiving countries like Australia and New Zealand. Such sex ratios contributed to lone inhabitancy, to childlessness, to many social problems, and to a telling abundance of lonely correspondence. Indeed, the huge surge of international migration from the early nineteenth century onwards produced a massive and poignant literature and balladry of solitary loneliness which awaits analysis. Prior to the 1960s, however, little is known about the incidence of solitaries, and the household analyses which are available have not addressed issues of loneliness.

Prior to the early twentieth century, and using sources from Britain, Europe, America and Japan, about 5 per cent of households were solitaries, which in England was about 1 per cent of the population $[67,68]$. Industrialisation, which in general terms we may date from the late eighteenth century in England and somewhat later in other countries, did not affect the incidence of solitaries. British nineteenthcentury industrial settlements shared the pre-industrial or nineteenth-century rural proportions of solitaries. While early signs of the rise of living alone can be cartographically detected from 1851 onwards in Britain (notably as elderly familial remnants of youthful rural out-migration), the frequencies of living alone stayed fairly steady from the preindustrial period into the early twentieth century. Across many types of community, the pre-1901 percentage rarely rose above 10 per cent for any place. Solitaries then grew from about 5 per cent to about 17 per cent in the 1960s, or 15 per cent in England and Wales. While this is significant, occurring largely in the mid-twentieth century, the major growth thereafter was to completely unprecedented levels. In the UK, by the 2011 census 31 per cent of households were solitaries. As in northern Europe or North America, this has particularly affected the elderly, though the fastest rate of growth of single-living has been for the 25-44 age group, in which men predominate among singletons in most countries. This rise in living alone traverses ages, it is not confined to the elderly. These solitaries are now enormously numerous compared to past history, or to the mid-twentieth century [69].

In sum, living-alone internationally displays post-1918 and especially post-1960s upsurges. At the extreme this has risen from zero per cent solitary households in very many English pre-industrial communities (and no doubt widely elsewhere), to the situation in modern Stockholm (over 60 per cent of households), or some parts of US cities. This trend appears to have global dimensions, but is most pronounced in Scandinavia, north-west Europe, Japan, and North America [69, p. 34-5]. Japan aside, these are predominantly Protestant countries characterised by nuclear families, carried to North America, Australia and New Zealand via major streams of emigration, where stem, extended, or 'peasant' family structures have been comparatively and internationally rare. Many cultural fundamentals of their legal systems (and gender ascriptions) were in effect transmitted under General MacArthur as Allied Commander in occupied Japan from 1945 to 1950, with varying degrees of success. Such a legal-cultural overlay may help to explain, alongside mutual economic and demographic factors, why Japan now shares Western rates of living alone and loneliness.

\section{INTERPRETATIONS OF THE WESTERN RISE IN LONE LIVING}

North-west European demographers refer to the phenomenon of 'nuclear-family hardship': by which they mean problems (including personal isolation, loneliness and welfare vulnerability) when the strongly prevalent nuclear family is disrupted, in highly wage-dependent/capitalist contexts with pronounced dependency ratios, a kin-weak culture, and separate-household marriages [70]. It is no coincidence, therefore, that the long-capitalist and migratory north European societies had to develop the most complex welfare states, and arguably did so from early periods, such as the 1601 'old poor law' framework for England and Wales, or its sophisticated early modern equivalents in the Netherlands. Their capitalist successes facilitated such welfare development, enabling for example complex rating and social transfer systems. Against that backdrop of cultural and economic demography, the attendant Nordic and northwest European 'welfare state' political ideologies might now appear inevitable, or at least logical outcomes, though the historical analysis and categorisation of welfare regimes at national or regional levels is still developing, and it is premature as yet to relate them to phenomena such as religion, living alone, or loneliness [71]. Certainly, and in complex ways, the 'failure' of such societies' nuclear families, their associated demography, socio-economic conditions, and probably even their 'high' tax-based formal welfare systems, have been both responses to deliberate, inadvertent, or feared isolation, and have accentuated living alone and perceptions or realities of 'the loneliness epidemic'.

There are many related causes of the growth of solitaries. Among these have been major shifts in the demographic structures of potential loneliness: lengthening life expectancies, changing marriage patterns and lessening remarriage, the decline in the birth rate, shifts in 
childlessness, changing mean age and duration of maternity, and increases in divorce. A range of other factors are clearly implicated, such as rising affluence, women's rights, the decline of the family as a primary producer, the erosion of live-in service and comparable institutions, the communications revolution, urbanisation and commuting, higher education growth, and individualistic ideologies. Rising real incomes allow more people to live alone by choice, in effect buying their privacy, a concept that has an interesting relation to loneliness. The feminist movements since the mid-1970s undermined cultural constraints against women living alone [72], increased female participation rates, and brought legal reforms in working rights. A history of feminism and loneliness remains to be written, and it is hard to judge what its arguments would be. In many Western cities, notably from the 1980 s, there has been considerable growth of managerial and professional women living alone [73-75]. It is also notable how high women's economic participation rates are in countries heading any international table of living alone, such as Finland, Sweden and Denmark. The 'full-time housewife' had a short history, and the implications for loneliness of shifts in what some economists would refer to as an earlier marital calculus of emotionaleconomic exchange remain unclear. It is possible, for example, that rising women's participation rates have relieved much feminine loneliness, while accentuating that of men - though such arguments across a variety of cultures could unfold in many ways. Most recently, the increase of 'living apart together' (LAT) relationships is influencing the growth of conventionally defined 'solitaries'. These relationships involve about 10 per cent of adults in Britain, and (in 1996-98) about 6.5 per cent in the USA, or about 35 per cent of US adults who are not married or cohabiting [7678]. Many other socio-cultural domestic arrangements influence growing solitaries, the emotional microgeographies and hybridity of which can blur conventional household boundaries and definitions (e.g. strategies of the growing numbers of single-parent families, non-heterosexual living arrangements, friendship substitutions for family, and so on).

The extent of single-living is now unparalleled. There has been a steep rise in the proportions of women never married [60]. Marriage rates are at historically low levels, for example in the UK and US falling notably since 1970 [3], while mean ages at first marriage are high. In England and Wales in 2009 they were 32.1 (male) and 29.9 (female). These have risen steeply since the mid-1960s, when respective ages were 23 and 21 , and especially since the mid1980 s, though rates of unmarried co-habitation have markedly increased. The birth rate was in long-term decline, and then fell steeply from 1964 in the UK. In Europe it has been notably low in recent decades. Fertility restraint occurred later rather than earlier in marriages, especially for younger marriages, producing extended 'empty nests' [79]. Childlessness has risen across many countries in recent decades [80]. The demographic prevalence of children (those aged under 15) is far less than before the twentieth century. They are now, in some accounts, discussed as risky assets or liabilities, a source of generational problems, an obstacle to individualistic careers [47]. With the falling birth rate has come declining kin connectivity, despite technologies of travel. The unmarried as a percentage of the older population have been increasing, and will probably continue to increase, as a result of divorce, widowhood, and extended life expectancy.

The rise of solitaries is not only a feature of ageing. In the USA, for example, about 5 million of those living alone are young adults aged 18-34, the fastest growing group of singletons. Over 15 million singletons are middle-aged adults aged 35-64. Those aged 65 or more comprise about 11 million people. Living alone and loneliness, insofar as they are related phenomena, are certainly not restricted to the elderly. In most countries earlier forms of young adult group living (service, live-in apprentices, bothies, lodgings, dormitories, etc) have declined, only partially replaced by some forms of student living. (Students in the UK comprise less than 1 per cent of those living alone). This has isolating repercussions for many young people, and for the older population with whom such people often hitherto resided $[72,73,81]$.

Two-person households have been rising steeply over the past century, and solitary-person households often arise from the failure (divorce, separation, death) of such households. This is pronounced in north-west Europe and emigrationrelated cultures, and, perhaps like loneliness, it is less marked in countries featuring joint household systems. Linking this to loneliness extends concepts of "nuclear family hardship': the problems that occur when the nuclear family is disrupted, especially in wage-dependent historical contexts with a high dependency rate, in the relatively kinweak cultures which characterise many Western societies, with their comparatively shallow kinship terminologies. Now and in the past, marriage in these cultures normatively involves setting up a separate household [70, 82, 83]. The decline of live-in persons, sharing a household, accentuates this effect. In most communities people have also become less inter-related, given high migration and falling birth rates.

Against this cultural and demographic background, itself highly indicative in relation to loneliness, divorce has risen markedly. Socio-economic changes, and issues of work-life balance and distances, have put huge strains upon marriage. In 1936, 6 per cent of marriages in Britain would divorce by their twentieth anniversary; now over a third is expected to do so. Movements in the UK divorce rate are very similar to Denmark, the USA, Canada, Australia and New Zealand. In 18 European countries, the divorce rate rose most sharply from 1970 to 1986, and has continued to rise [84, p. 25]. It is true that many divorce petitions historically mention loneliness, making them an ideal source for the study of loneliness within marriage, among those who do not live alone. However, given the high correlations repeatedly found between marital break-up, living alone and self-rated loneliness, such post-1945 changes would seem to have significant repercussions for loneliness as a societal experience.

Social trends have accentuated the longer-term tendency for the Western nuclear family to predominate, and the break-up of two-person households and resulting isolation of the aged has become obvious since $1950[85,86]$. In the UK, as elsewhere, solitaries are conspicuous in retirement areas: 
phenomena of widowhood affecting small nuclear families. Internationally speaking, these 'atomising' features, as with all forms of single-person households, are now most extreme in north-west Europe, Japan, and to a slightly lesser degree North America. Emigration-transmitted family formation systems and resulting structures have increased personal isolation, notably among the elderly. These dominant small nuclear-families, as analysed by many demographers since John Hajnal [87, 88], have come through history to contribute to (or even define) the problems outlined in this article. Historical cultural ideologies of individualistic pride, which continue relentlessly in many countries, coupled with strong senses of privacy, have compounded isolation and loneliness. An array of related social changes - such as divorce, extended life expectancies, declining marriage and birth rates, migration-disrupted kinship, affluence influencing housing choices, de-industrialisation and its population displacements - conduce to the present-day prevalence of solitaries, seemingly accentuating the selfreported loneliness now widely described as 'the loneliness epidemic' and 'time bomb' of Western societies.

\section{CONCLUSION}

At many points this discussion has alluded to the complexity and lateral range of the historical issues, concepts and questions, which cannot be handled with fullness in an academic article. These are culturally nuanced, and very variably expressed in historical documentation across many cultures and languages. By contrast with many more easily definable areas of historical research, histories of the subjective condition of loneliness could adopt quite differing emphases, mediated by a historian's personal experiences of this emotion. However, this article has pointed to some of the chief questions, and some prominent approaches, which broach these issues historically, and which allow this to develop as an historical genre aiming to place studies of modern loneliness into an historical context. Relatively developed research on historic household forms, although it was not focused on loneliness as a problem in the work of Laslett and his associates [67, 68], opens up one perspective on the rise of living alone. Regional or national differences in lone living may also be suggestive, relating for example to past religious cultures, and they may have a number of connections to modern loneliness. Strong Protestant traditions, for example in north-west Europe and Scandinavia, with very dominant nuclear families, might render their citizens more culturally 'self-reliant', or proudly immune to self-declared loneliness, although as secularisation progresses this may become less evident. A more confessional, hierarchical or Catholic culture, as in southern Europe, coupled with more complex family forms, may be a safeguard against loneliness, again subject to the culturally delayed effects of secularisation. Disruption of such norms may make Mediterranean peoples more prone to report loneliness, as it contravenes expectations, more so perhaps than in Scandinavia.

Living alone and its possible correlates, which remain to be explored more fully, may be one possible way of trying to anchor the history of loneliness, and to supply one dimension of long-term change. However, when we address possible links between living alone and loneliness, we certainly need to bear in mind that solitary residency is neither a necessary nor a paramount determining feature of loneliness. And if lone living stands in some qualified degree as a proxy loneliness indicator or predictor variable in post-1945 quantitative analyses, there still would remain questions about whether it might do so in earlier historical and crosscultural experience.

If the striking upward trajectory of solitaries or singletons in Western societies has meaning for the interpretation of loneliness in historical perspective, it might appear to be a stark one; yet a fuller appraisal requires much broader sociohistorical and cultural analysis using other historical sources beyond listings of inhabitants and household censuses. It will need, inter alia, to evaluate how certain issues and groups became identified as social problems expressive of or epitomising loneliness. And it will need to consider humanitarian or ostracising social responses to those predicaments and states of mind, and the relative tolerances of differing cultures and nations. When and why, for example, did concern about loneliness among older people become apparent? And why did such a preoccupation with elderly loneliness, when it finally became very noticeable, in Britain probably in the 1940s onwards, so often eclipse loneliness among younger adults, let alone children? Why is the loneliness of children such a recent social policy issue, even though it was tellingly (and autobiographically) obvious to novelists such as Charles Dickens, given nineteenth-century high orphanage? When and why did social policy and researchers become interested or even empowered in the 'private' sphere of social relationships, as is now usually evident in modern loneliness studies and much welfare work or concern? Such questions facing historians are not rhetorical: they are important and keep asserting themselves. It is too early as yet to stake out a central and nationally comparative historical narrative here, let alone to expound longer-term historical theory to supplement that of the social sciences. But this article opens up some avenues for research, and broaches many of the issues that will become apparent as the international history of loneliness develops.

\section{CONFLICT OF INTEREST}

The author confirms that this article content has no conflict of interest.

\section{ACKNOWLEDGEMENTS}

Declared none.

\section{REFERENCES}

[1] Wood LA. Loneliness. In: Harré R, Ed. The social construction of emotions. Oxford: Blackwell 1986.

[2] Rokach A, Orzeck T, Cripps J, Lackovic-Grgin K, Penezic Z. The effects of culture on the meaning of loneliness. Soc Indic Res 2001; 53(1): 17-31.

[3] Offer A. The challenge of affluence: self-control and well-being in the United States and Britain since 1950. Oxford: Oxford University Press 2006.

[4] Kar-Purkayastha I. An epidemic of loneliness. Lancet 2010; 376: 2114-15.

[5] Khaleeli H. Britain's loneliness epidemic. UK: Guardian 2013.

[6] Killeen C. Loneliness: an epidemic in modern society. J Adv Nurs 1998; 28(4): 762-70 
[7] Rokach A. Alienation and domestic abuse: how abused women cope with loneliness. Soc Indic Res 2006; 78(2): 327-40.

[8] Rokach A, Brock H. Loneliness: a multidimensional experience. Psychol J Hum Behav 1997; 34(1): 1-9.

[9] Victor CR, Bowling A. A longitudinal analysis of loneliness among older people in Great Britain. J Psychol 2012; 146(3): 313-31.

[10] Griffin J. The lonely society? London: Mental Health Foundation 2010.

[11] Yang K, Victor C. Age and loneliness in 25 European nations. Ageing Soc 2011; 31(8): 1368-88.

[12] Asher SR, Hymel S, Renshaw PD. Loneliness in children. Child Development 1984; 55(4): 1456-64.

[13] Hutchison D, Woods R. ChildLine casenotes: children talking to ChildLine about loneliness. London: NSPCC 2010.

[14] Beach B, Bamford S-M. Isolation: the emerging crisis for older men. London: Independent Age 2014.

[15] Rowntree BS. Old people: Report of a survey committee on the problems of ageing and the care of old people. London: Nuffield Foundation 1947.

[16] Sheldon JH. The social medicine of old age: report of an enquiry in Wolverhampton. London: Oxford University Press/Nuffield Foundation 1948.

[17] Townsend P. Social surveys of old age in Great Britain, 1945-58. Bull World Health Org 1959; 21: 583-91.

[18] Andersson L. Loneliness research and interventions: a review of the literature. Aging Ment Health 1998; 2(4): 264-74.

[19] McWhirter BT. Loneliness: a review of current literature, with implications for counseling and research. J Couns Develop 1990; 68(4): 417-22.

[20] Klinenberg E. I want to be alone: the rise and rise of solo living. UK: Guardian 2012.

[21] Klinenberg E. Going solo: the extraordinary rise and surprising appeal of living alone. London: Duckworth Overlook 2014.

[22] Russell D. UCLA loneliness scale (version 3): reliability, validity, and factor structure. J Pers Assess 1996; 66(1): 20-40.

[23] Cacioppo JT, Christakis NA, Fowler JH. Alone in the crowd: the structure and spread of loneliness in a large social network. J Pers Soc Psychol 2009; 97(6): 977-91.

[24] Cacioppo JT, Patrick W. Loneliness: human nature and the need for social connection. New York: W.W. Norton 2008.

[25] Drennan J, Treacy M, Butler M, et al. The experience of social and emotional loneliness among older people in Ireland. Ageing Soc 2008; 28(8): 1113-32.

[26] Porter M. Loneliness and your health. UK: The Times 2011.

[27] Rokach A. Coping with loneliness among the terminally ill. Soc Indic Res 2007; 82(3): 487-503.

[28] Shankar A, McMunn A., Banks J, Steptoe A. Loneliness, social isolation, and behavioral and biological health indicators in older adults. Health Psychol 2011; 30(4): 377-85.

[29] Segrin C, Burke TJ, Dunivan M. Loneliness and poor health within families. J Soc Pers Relat 2012; 29(5): 597-611.

[30] Shiovitz-Ezra S, Ayalon L. Situational versus chronic loneliness as risk factors for all-cause mortality. Int Psychogeriatr 2010; 22(3): 455-62.

[31] Tilvis RS, Laitala V, Routasalo PE, Pitkälä KH. Suffering from loneliness indicates significant mortality risk of older people. J Aging Res 2011; 2011: 534781.

[32] Victor CR, Scambler SJ, Bowling A, Bond J. The prevalence of, and risk factors for, loneliness in later life: a survey of older people in Great Britain. Ageing Soc 2005; 25(3): 357-75.

[33] Victor CR, Yang K. The prevalence of loneliness among adults: a case study of the United Kingdom: J Psychol 2012; 146(1): 85-104.

[34] Putnam RD. Bowling alone: the collapse and revival of American community. New York: Simon \& Schuster 2000.

[35] Pinquart M, Sörenson S. Influences on loneliness in older adults: a meta-analysis. Basic Appl Soc Psychol 2001; 23(4): 245-66.

[36] Dumm T. Loneliness as a way of life. Cambridge: Harvard University Press 2008.

[37] de Jong-Gierveld J. A review of loneliness: concepts and definitions, determinants and consequences. Rev Clin Gerontol 1998; 8: 73-80.

[38] Sadler WA. Dimensions in the problem of loneliness: a phenomenological approach in social psychology. J Phenomenol Psychol 1978; 9(1): 157-87.

[39] Weiss RS, Ed. Loneliness: the experience of emotional and social isolation. Cambridge: M.I.T. Press 1973.
[40] Turner T. The diary of a Georgian shopkeeper. Oxford: Oxford University Press 1979.

[41] Beaumont J. Households and families: social trends, 41. London: ONS 2011.

[42] de Tocqueville A. Democracy in America. New York: Collins 1968.

[43] Engels F. The condition of the working class in England. London: Panther 1984.

[44] Tönnies F. Gemeinschaft und gesellschaft; trans: Community and society. Cambridge: Cambridge University Press 2001.

[45] Beck U. Risk society: towards a new modernity. London: Sage 2007.

[46] Connerton P. How modernity forgets. Cambridge: Cambridge University Press 2009.

[47] Baumann Z. Liquid love: on the frailty of human bonds. Cambridge: Polity 2003.

[48] Buzar SA, Ogden PE, Hall R. Households matter: the quiet demography of urban transformation. Prog Hum Geogr 2005; 29(4): 413-36.

[49] Lesthaeghe R. 2011. The unfolding story of the second demographic transition. Popul Dev Rev 2011; 36(2): 211-51.

[50] Defoe D. Robinson Crusoe. Oxford: Oxford University Press 2008.

[51] Burton R. The anatomy of melancholy. New York: NYRB Classics 2001.

[52] Armon-Jones C. Prescription, explication and the social construction of emotion. J Theor Soc Behav 1985; 15(1): 1-22.

[53] Anderson R, Dubois H, Leončikas T. and Sándor E. $3^{\text {rd }}$ European quality of life survey: quality of life in Europe: impacts of the crisis. Luxembourg: Publications Office of the European Union 2012.

[54] Houellebecq M. Atomised. London: Vintage Books 1999.

[55] Straus AS. The meaning of death in northern Cheyenne culture. In Robben ACGM, Ed. Death, mourning, and burial: a cross-cultural reader. Oxford: Blackwell 2004

[56] Kolker R. A cinema of loneliness. Oxford: Oxford University Press 2011.

[57] Augé M. Non-Places: introduction to an anthropology of supermodernity. London: Verso Books 2009.

[58] Burris CT, Batson CD, Altstaedten M, Stephens, K. "What a friend...": loneliness as a motivator of intrinsic religion. J Sci Study Relig 1994; 33(4): 326-34.

[59] Paloutzian RF, Janigian AS. Interrelationships between religiousness and loneliness. Psychother Patient 1986; 2(3): 3-14.

[60] Castells M. The information age: economy, society and culture. Vol. 2: The power of identity. Oxford: Blackwell 2007.

[61] Berdyaev N. Solitude and society. London: Centenary Press 1947.

[62] Watson J, Campbell G. Yukon memories: A Mountie's story. Vancouver: Whitecap Books 1993.

[63] Martin BP. Tales of the old gamekeepers. Newton Abbot: David \& Charles 1989.

[64] Parker T. Lighthouse. London: Hutchinson 1975.

[65] Brody H. Inishkillane: change and decline in the west of Ireland. London: Jill Norman \& Hobhouse 1973.

[66] Scheper-Hughes N. Saints, scholars, and schizophrenics: mental illness in rural Ireland. Berkeley: University of California Press 1979.

[67] Laslett P. Family life and illicit love in earlier generations. Cambridge: Cambridge University Press 1977.

[68] Laslett P, Wall R, Eds. Household and family in past time. Cambridge: Cambridge University Press 1972.

[69] Jamieson L, Simpson R. Living alone: globalization, identity and belonging. Palgrave: Macmillan 2013.

[70] Smith R. Charity, self-interest and welfare: reflections from demographic and family history. In: Daunton M, Ed. Charity, selfinterest and welfare in the English past. London: UCL Press 1996.

[71] King SA. Welfare regimes and welfare regions in Britain and Europe, c. 1750s to 1860s. J Mod Eur Hist 2011; 9(1): 44-67.

[72] Hareven TK, Tilly LA. Solitary women and family mediation in America and French textile cities. Annales de démographie historique 1981; 17: 253-71.

[73] Hall R, Ogden, PE, Hill C. The pattern and structure of one-person households in England and Wales and France. Int J Popul Geogr 1997; 3: 161-81.

[74] Ogden PE, Hall R. Households, reurbanisation and the rise of living alone in the principal French cities, 1975-90. Urban Stud: 2000; 37(2): 367-90. 
[75] Hall R, Ogden PE. The rise of living alone in Inner London: trends among the population of working age. Environ Plann A 2003; 35(5): 871-88.

[76] Levin I. Living apart together: a new family form. Curr Sociol 2004; 52(2): 223-40.

[77] Strohm CQ, Seltzer JA, Cochran SD, Mays VM. "Living apart together" relationships in the Unites States. Demogr Res 2009; 21: 177-214.

[78] Villeneuve-Gokalp C. Vivre en couple, chacun chez soi. Population 1997; 52(5): 1059-82.

[79] Anderson M. Fertility decline in Scotland, England and Wales, and Ireland: comparisons from the 1911 census of fertility. Popul Stud 1998; 52(1): 1-20.

[80] Rowland DT. Historical trends in childlessness. J Fam Issues 2007; 28(10): 1311-37.

[81] Snell KDM. Annals of the labouring poor: social change and agrarian England, 1660-1900. Cambridge: Cambridge University Press 1985.
[82] Laslett P. Family, kinship and collectivity as systems of support in preindustrial Europe: a consideration of the "nuclear hardship hypothesis". Contin Change 1988; 3(2): 153-75.

[83] Smith JE. Widowhood and ageing in traditional English society. Ageing Soc 1984; 4(4): 429-49.

[84] Gonzalez L, Viitanen TK. The effect of divorce laws on divorce rates in Europe. Discussion Paper No. 2023. Bonn, Germany: Institute for the Study of Labor (IZA) 2006.

[85] Laslett P. A fresh map of life: the emergence of the third age. London: Weidenfeld \& Nicolson 1989.

[86] Wall R. The living arrangements of the elderly in contemporary Europe in the 1980s. In: Bytheway B, Keil T, Allatt P, Bryman A, Eds. Becoming and being old: sociological approaches to later life. London: Sage 1989.

[87] Hajnal J. European marriage patterns in perspective. In: Glass DV, Eversley DEC, Eds. Population in history: essays in historical demography. London: Edward Arnold 1965.

[88] Hajnal J. Two kinds of preindustrial household formation system. Popul Dev Rev 1982; 8(3): 449-94.

(C) K. D. M. Snell; Licensee Bentham Open.

This is an open access article licensed under the terms of the Creative Commons Attribution Non-Commercial License (http://creativecommons.org/licenses/by-nc/3.0/) which permits unrestricted, non-commercial use, distribution and reproduction in any medium, provided the work is properly cited. 